\title{
Editorial
}

\section{Advanced materials and nanotechnology cluster}

Buildings are the largest consumer of energy and the largest emitter of greenhouse gases. More than $50 \%$ of the residential buildings in Europe were built before 1970; thus renovation and upgrading of the existing building stock is a priority in the EU energy policies and for all the EU member states. The increasing focus on energy conservation necessitates the adoption of innovative materials. Government regulations and support for zero energy buildings provide an impetus to the adoption of innovative materials (Directive 2010/31/EU).

AMANAC is a collaboration and coordination platform across all of the EU funded Advanced Materials and Nanotechnology projects within the framework of the Energy Efficiency in Buildings Public Private Partnership (EeB-PPP); its activities address development of advanced materials, components and systems for the improvement of the energy efficiency in the built environment. AMANAC is a cluster of 29 projects, representing 255 project partners, 63\% of which are large enterprises or SMEs. AMANAC aims to maximize the impact of the AMANAC projects on the European Industry and Society. More information about AMANAC can be found at http://amanac.eu/

The adoption of innovative materials in building envelopes offers great potential for future design and construction. This is why the Journal of Facade Design and Engineering dedicates this special issue to this topic. JFDE is a firm partner for the distribution of scientific knowledge of the ICAE2015 International Congress on Architectural Envelopes (www.icae2015.com/en), organised by Tecnalia in San Sebastian, Spain.

The papers presented in this current issue originate from five AMANAC research projects that researched new advanced materials and systems for energy efficient buildings. The works have been selected among the AMANAC project research results, initially presented in a special session at ICAE2015. The extended papers have been subjected to the regular double blind review process of the journal.

Guest Editors Maria Founti

School of Mechanical Engineering National Technical University of Athens, Greece E-mail: mfou@central.ntua.gr.

Julen Astudillo Larraz Sustainable Construction Division

TECNALIA, Spain

E-mail: julen.astudillo@tecnalia.com.

Editors in chief Ulrich Knaack and Tillmann Klein 